\title{
Right Sided Facial Nerve Palsy, Bilateral Microtia with Polydactyly in an Infant - A Rare Case Report
}

\author{
Shruti Chaudhary ${ }^{1}$, Gyanavelu Injeti², Amar Taksande ${ }^{3}$, Revat Meshram4, Amol Lohkare ${ }^{5}$ \\ 1,2, 3, 4, 5 Department of Paediatrics, Jawaharlal Nehru Medical College, Sawangi, Wardha, Maharashtra, India.
}

\section{INTRODUCTION}

Congenital facial palsy (CFP) is facial palsy of the seventh cranial nerve present at birth. It is commonly believed to be either developmental or originally acquired. Facial palsy of developmental origin is associated with other anomalies including ear, eye or cardiac anomalies. But it is rarely associated with polydactyly. We report a 10 month-old female infant who had right CFP with bilateral microtia and polydactyly.

Congenital facial nerve palsy unilaterally manifesting as weakness of entire face on one side due to infranuclear cause is a rare occurrence in paediatric population. ${ }^{1}$ The facial palsy of lower motor neuron type involves weakness of same side of muscles of face of one side. Facial nerve as it emerges out of cranium traverses through facial canal medial to mastoid process and divides into multiple branches. It supplies ear, autonomic fibres for lacrimal gland, salivary glands, and motor supply to the face. Any pathology, congenital or acquired causing compression of facial nerve in this pathway can lead to facial palsy. Microtia is a congenital condition that varies from minor structural defects to full ear absence in severity and may occur as an individual defect or as part of a syndrome. Polydactyly is the most common hereditary limb anomaly characterized by extra fingers or toes. Here, we report a case presented with bilateral microtia and right-side facial nerve palsy.

\section{PRESENTATION OF CASE}

A 10-month-old female infant born out of non-consanguineous marriage was brought with the complaint of facial asymmetry and deformity of both ears since birth. The child was born prematurely via Caesarean section at 34 weeks of gestation with birth weight of $1.2 \mathrm{~kg}$ without birth asphyxia. The mother had polyhydramnios and gestational hypertension. There was no history suggestive of intrauterine infection or drug intake during pregnancy. In view of very low birth weight and prematurity, the baby was kept in neonatal intensive care unit (NICU) for 25 days. At birth, the child had small pinna bilaterally and facial deformity. At 1 month of age, patient was diagnosed to have retinopathy of prematurity for which she was operated at 3 months of age. There was no family history of congenital malformations.
Corresponding Author: Dr. Amar M. Taksande, Department of Paediatrics, Jawaharlal Nehru Medical College, Sawangi, Wardha, Maharashtra, India. E-mail:amar.taksande@gmail.com

DOI: $10.14260 / j e m d s / 2021 / 285$

How to Cite This Article:

Chaudhary S, Injeti G, Taksande A, et al. Right sided facial nerve palsy, bilateral microtia with polydactyly in an infant - a rare case report. J Evolution Med Dent Sci 2021;10(18):1353-1355, 10.14260/jemds/2021/285

Submission 17-12-2020,

Peer Review 06-03-2021,

Acceptance 12-03-2021,

Published 03-05-2021.

Copyright (c) 2021 Shruti Chaudhary et al. This is an open access article distributed under Creative Commons Attribution License [Attribution 4.0 International (CC BY 4.0)] 
Her weight was $7.4 \mathrm{~kg}$, height of $65 \mathrm{~cm}$ and head circumference was $42 \mathrm{~cm}$. Her vitals were: Heart rate: 110 / min, respiratory rate: 36 / $\mathrm{min}$, blood pressure: 84 / $56 \mathrm{mmHg}$ and Spo2: 98 \%. On general examination, facial deformity, bilateral small pinna (microtia, grade III) (Figure 1), right preaxial polydactyly were present. Neurological examination was suggestive of right sided lower motor neuron facial palsy suggested by inability to close the right eye completely and loss of a nasolabial fold on the same side (Figure 2). Absence of forehead wrinkles and asymmetric faces with the right lower lip being pulled down while crying was also seen. Left eye closure and nasolabial fold were normal. There was no other cranial nerve palsy and the remainder of the neurological examination was normal. Respiratory, cardiovascular and abdominal examination were normal. Spine and genitalia were normal. On investigations, haemoglobin was $11.2 \mathrm{gm} \%$, total leukocyte count 7,000 / cumm, platelet count 1.55 lakhs and peripheral smear showed normocytic normochromic RBCs. Liver function test and renal function test were normal. Brainstem evoked response audiometry showed VTH wave formation at $100 \mathrm{~dB}$ in both ears suggestive of moderate sensory neural hearing loss. Abdominal ultrasonography, transthoracic echocardiogram, cranial ultrasonography and ophthalmological examination were normal.
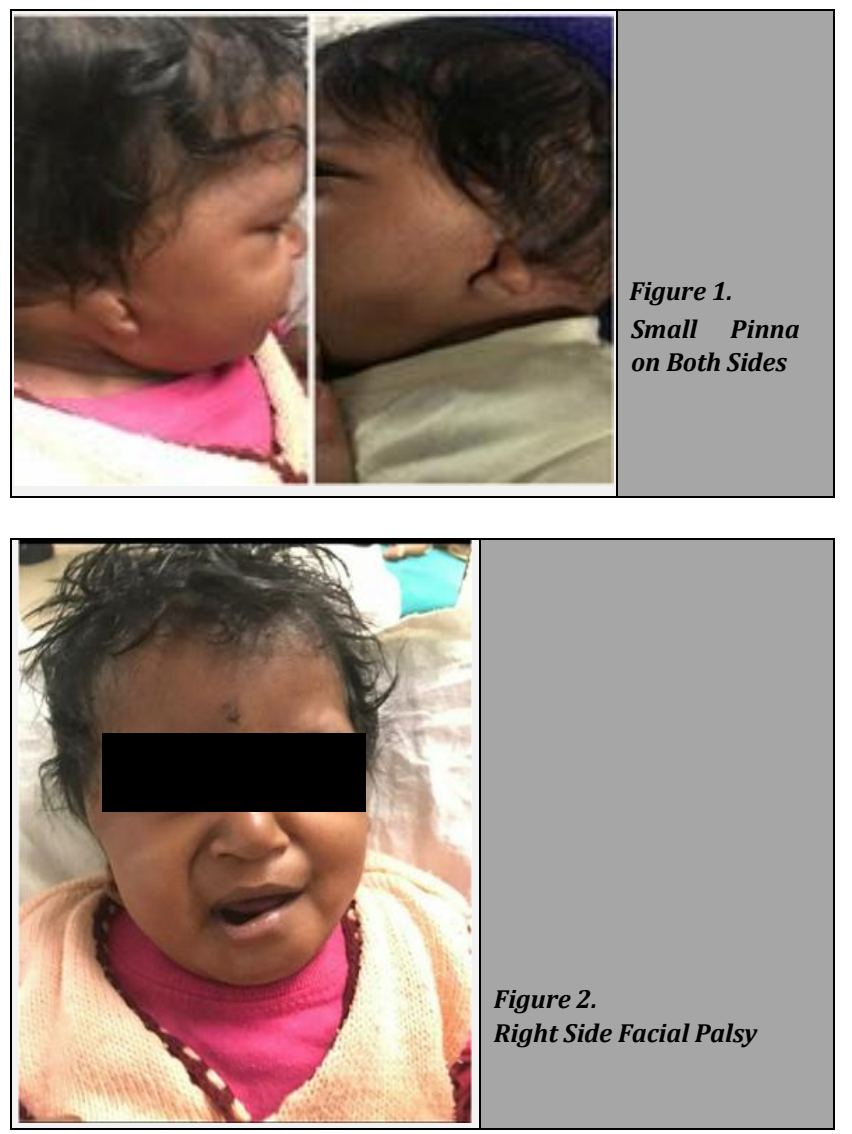

\section{DISCUSSION}

An uncommon disorder with an occurrence of 2.1 in 1,000 live births is congenital facial nerve paralysis. ${ }^{2}$ It is typically associated with birth injury in 78 percent of cases. ${ }^{3}$ Congenital facial palsy is clinically defined as facial palsy of the seventh cranial nerve which is present at birth or shortly thereafter. The facial nerve is compromised and compressed due to particular anatomical course making it difficult to navigate and sustain inflammatory response in a tight space. This makes unique value proposition for trauma to the nerve and following weakness. The $7^{\text {th }}$ cranial nerve may not be developed properly due to agenesis or partial development of temporal bone. The adjoining area of mastoid process and ear cartilage is also affected. Kulkarni et al. ${ }^{3}$ and Mahali RR ${ }^{4}$ have reported case on facial nerve palsy with ear anomaly. Other congenital anomalies associated include cleft palate, hypoplastic maxilla, renal defects and heart defects. Association of ear-pinna defects and facial palsy has been reported in $10-15 \%$ of patients. Absence of pinna occurs in around 1 in 20000 live births. Other syndromes associated with ear deformity and facial nerve palsy like velo-cardiofacial, Moebius syndrome, Poland's syndrome, Goldenhar's syndrome, Lambert and Townes Brocks syndrome.5,6 Velocardio-facial syndrome has vertebral and cardiac defects, Moebius syndrome includes abducent nerve palsy; Poland syndrome has absence of pectoralis major muscle; Goldenhar syndrome involves entire half of the face along with cardiac defects. ${ }^{7}$ Lambert syndrome includes brachial dysplasias, cholestasis, inguinal hernia and club foot and Townes Brocks syndrome includes imperforate anus, thumb malformations. ${ }^{8}$ Our case report is different from others, in this report along with facial nerve palsy and bilateral microtia, patient also had polydactyly.

\section{FINAL DIAGNOSIS}

Cranio Facial Palsy with bilateral anotia and external auditory canal atresia with polydactyly in an infant.

Financial or other competing interests: None.

Disclosure forms provided by the authors are available with the full text of this article at jemds.com.

\section{REFERENCES}

[1] Van Meter TD, Weaver DD. Oculo-auriculo-vertebral spectrum and the CHARGE association: clinical evidence for a common pathogenetic mechanism. Clin Dysmorphol 1996;5(3):187-96.

[2] Falco NA, Eriksson E. Facial nerve palsy in the newborn: incidence and outcome. Plast Reconstr Surg 1990;85(1):1-4.

[3] Kulkarni S, Verma S, Kavthekar SO, et al. Congenital facial palsy with anotia and congenital heart disease in infants: a rare presentation. Int $\mathrm{J}$ Med Paediatr Oncol 2019;5(4):149-50.

[4] Mahale RR, Mehta A, John AA, et al. Newborn with congenital facial palsy and bilateral anotia / atresia of external auditory canal: rare occurance. J Pediatr Neurosci 2016;11(3):271-3.

[5] Bergstrom L, Baker BB. Syndromes associated with congenital facial paralysis. Otolaryngol Head Neck Surg 1981;89(2):336-42. 
[6] Jemec B, Grobbelaar A0, Harrison DH. The abnormal nucleus as a cause of congenital facial palsy. Arch Dis Child 2000;83(3):256-8.
[7] Taksande A, Vilhekar K. Oculoauriculovertebral spectrum with radial anomaly in child. J Family Med Prim Care 2013;2(1):92-4.

[8] Ciaorba A, Corrzzi V, Cons V, et al. Facial nerve paralysis in children. World J Clin Cases 2015;3(12):973-9. 